Research, Society and Development, v. 7, n. 7, p. 01-23, e1077302, 2018

ISSN 2525-3409 (CC BY 4.0)

\title{
Geobiologia: o ensino da evolução da vida na Terra
}

Geobiology: teaching the evolution of life on Earth

Juni Cordeiro

Fundação Comunitária de Ensino Superior de Itabira, Brasil

E-mail: juni.cordeiro@funcesi.br

Cibele Andrade de Alvarenga

Fundação Comunitária de Ensino Superior de Itabira, Brasil

E-mail: cibele.alvarenga@funcesi.br

Renato Kerley Lage Torres

Grupo de Estudos de Astronomia e Astronáutica, Brasil

E-mail: cibele.alvarenga@funcesi.br

E-mail: renatokerleytorres@yahoo.com.br

Tárik Silveira Cordeiro

Fundação Comunitária de Ensino Superior de Itabira, Brasil

E-mail: tarik.cordeiro@globo.com

Hendiel Aparecida de Abreu

Fundação Comunitária de Ensino Superior de Itabira, Brasil

E-mail: hendielmix@ @otmail.com

Guilherme Henrique Rodrigues de Assis

Fundação Comunitária de Ensino Superior de Itabira, Brasil

E-mail: guilhermehrassis @ yahoo.com.br

Daiane Fernandes Alvarenga

Fundação Comunitária de Ensino Superior de Itabira, Brasil

E-mail: daialvarenga15@gmail.com

Aline Dias de Sá

Fundação Comunitária de Ensino Superior de Itabira, Brasil

E-mail: alinediasdesa@hotmail.com

Recebido: 01/03/2018 - Aceito: 06/04/2018

\section{Resumo}

As histórias geológica e ecológica da Terra estão diretamente vinculadas, assim, compreender os principais processos que constituíram e modificaram a Terra, além de permitir desvendar uma parte do passado do planeta, pode auxiliar a entender o tempo atual e ainda vislumbrar o 
futuro. O projeto de extensão Geobiologia, desenvolvido na Fundação Comunitária de Ensino Superior de Itabira - FUNCESI (MG), possui como objetivo principal a divulgação das ciências naturais, buscando a compreensão da formação, evolução e futuro da vida na Terra. Este trabalho visa analisar a percepção acerca dos conceitos de geociências de 413 alunos que visitaram o projeto Geobiologia no ano de 2017. Para tal, foi aplicado um mesmo questionário antes e após o desenvolvimento das atividades vinculadas ao projeto. A partir dos resultados obtidos, foi possível notar a assimilação de conceitos referentes à idade do Universo e da Terra, por outro lado, a utilização de explanações, imagens e vídeos não se mostrou suficiente para a compreensão satisfatória dos conceitos associados à tectônica de placas e primeiras formas de vida na Terra. A utilização de réplicas de fósseis, assim como a manipulação de minerais e rochas, além de tornarem as atividades mais dinâmicas, foram descritas pelos alunos participantes como a parte mais "legal" do projeto. Espera-se que este projeto proporcione aos estudantes uma melhor compreensão da correlação entre as várias ciências da natureza e suas aplicações no cotidiano, além de despertar a importância da preservação ambiental em todos os setores da sociedade.

Palavras-chave: Eras geológicas; Evolução dos seres vivos; Preservação ambiental.

\begin{abstract}
The Earth's geological and ecological histories are directly linked to understanding the major processes that constituted and modified the Earth, as well as uncovering a part of the planet's past, can help us understand the current time and still glimpse the future. The Geobiology extension project, developed at the Fundação Comunitária de Ensino Superior de Itabira - FUNCESI (MG), has as main objective the dissemination of the natural sciences, seeking an understanding of the formation, evolution and future of life on Earth. Thus, this study aims to analyze the perception about the geosciences concepts of 413 students who visited the Geobiology project in the year 2017. For such, a same questionnaire was applied before and after the development of the activities related to the project. From the results obtained, it was possible to notice the assimilation of concepts related to the age of the Universe and the Earth, on the other hand, the use of explanations, images and videos was not enough for a satisfactory understanding of the concepts associated with plate tectonics and first forms of life on Earth. It should be noted that the use of fossil replicas, as well as the manipulation of minerals and rocks, besides making the activities more dynamic, were described by the participating students as the most cooler part of the project. Thus, it is expected that this project will provide students with a better understanding of the correlation between the various natural sciences and their applications in everyday life, in addition to raising the importance of environmental preservation in all sectors of society.
\end{abstract}


Keywords: Geological ages; Evolution of living beings; Environmental preservation.

\section{Introdução}

Preparar o estudante para a prática da cidadania significa deixá-lo apto a participar de forma ativa na sociedade, ação esta que envolve a compreensão, a análise e o julgamento acerca dos problemas que podem estar presentes tanto em sua comunidade local como no planeta. Contudo, para se atingir este propósito, as disciplinas escolares, principalmente, aquelas voltadas para o ensino das ciências, devem possuir características problematizadoras, não se limitando às fórmulas ou informações sem vínculo com o cotidiano do discente, mas compostas por instrumentos que podem ser empregados para a resolução de problemas sociais (SANTANA; SANTOS, 2009).

Uma vez que a biosfera está relacionada à litosfera, atmosfera e hidrosfera, podendo influenciar e até mesmo controlar os processos climáticos e geológicos básicos, surgiu a Geobiologia, que corresponde ao estudo dessas interações, envolvendo o ambiente físico da Terra e a biosfera (GROTZINGER; JORDAN, 2013).

No entanto, quando consideradas as ciências naturais, é possível observar que a Paleontologia nas escolas brasileiras não é devidamente abordada, sendo tratada principalmente dentro do tema "Evolução" (DANTAS; ARAÚJO, 2006).

Já com relação às Geociências, especialmente a Geologia, apesar de contribuir para uma percepção integrada e sistêmica do ambiente, não está inserida no currículo escolar como disciplina, tendo seu conteúdo disperso em outras áreas do conhecimento, como Ciências e Geografia, no ensino fundamental, e Física, Química e Biologia, no ensino médio (TOLEDO, 2005). Além disso, de acordo com Carneiro et al. (2004), os conceitos associados às Geociências não são comumente abordados de forma experimental, dificultando o estabelecimento de uma relação de aprendizagem simplificada entre a teoria e a realidade.

Dessa forma, faz-se necessário que a percepção dos alunos em relação às ciências naturais esteja vinculada ao entendimento da posição privilegiada do homem no tempo, no espaço e ao longo da evolução da vida, assim como também das consequências de suas ações diretas e indiretas na exploração do planeta e de seus recursos naturais (CERVATO; FRODEMAN, 2013).

Neste contexto, o projeto Geobiologia, desenvolvido por professores e alunos da Fundação Comunitária de Ensino Superior de Itabira - FUNCESI (MG), visa divulgar as ciências naturais na busca pela compreensão da formação, evolução e futuro da vida na Terra, 
utilizando para isso atividades práticas e equipamentos audiovisuais. Desse modo, este artigo objetiva analisar a percepção dos alunos visitantes acerca dos conceitos de geociências verificados antes e após o desenvolvimento das atividades vinculadas ao projeto Geobiologia.

\section{Metodologia}

Esta pesquisa utilizou uma abordagem quali-quantitativa. De acordo com Prodanov e Freitas (2013), a pesquisa quantitativa considera que tudo pode ser quantificado, traduzindo em números informações e opiniões para classificá-las e analisá-las. Desse modo, essa abordagem utiliza recursos e técnicas estatísticas, tais como porcentagem, média, mediana, desvio-padrão, dentre outros. Já a pesquisa qualitativa não utiliza ferramentas estatísticas, sendo comumente decorrente de estudos teóricos, exploratórios documentais e outros que tenham como característica a investigação histórica ou lógica (LEITE, 2008).

Para a coleta dos dados utilizou-se questionário, que corresponde a um instrumento formado por uma série de perguntas ordenadas, respondidas por escrito, sem a presença do pesquisador (MARCONI: LAKATOS, 2003). Neste estudo foi aplicado um mesmo questionário a 413 alunos que visitaram as dependências da Fundação Comunitária de Ensino Superior de Itabira (FUNCESI), provenientes de escolas estaduais, particulares e municipais de Itabira (MG) e região, antes e após as atividades desenvolvidas no projeto, a fim de avaliar o conhecimento prévio e após estas ações. Destaca-se que o questionário aplicado continha dez questões de múltiplas escolhas relacionadas à origem do universo e da Terra, teoria da tectônica de placas, evolução da vida na Terra e meio ambiente. Além disso, ao final das atividades, os alunos visitantes, em grupos de 3 a 5 indivíduos, preenchiam um segundo questionário que visava avaliar o nível de satisfação com as ações desenvolvidas, assim como obter sugestões e comentários quanto à execução das atividades.

O tratamento dos dados obtidos nesta pesquisa ocorreu por meio da estatística descritiva e análise de conteúdo. Conforme Appolinário (2016), a estatística descritiva é empregada para a descrição, resumo e apresentação gráfica dos dados obtidos na pesquisa quantitativa; enquanto a análise de conteúdo visa a busca do significado de dados textuais, como artigos de periódicos ou transcrição de entrevistas individuais ou coletivas. Assim, as informações obtidas por meio dos questionários foram tabuladas em planilha Excel e tratadas no software estatístico SPSS (Statistical Package for the Social Sciences), desenvolvido pela IBM (International Business Machines), versão 22.

As atividades do projeto de extensão Geobiologia foram desenvolvidas no Laboratório 
de Geologia da FUNCESI, por professores desta instituição com formação acadêmica nas áreas de Biologia e Geologia, e por alunos voluntários do curso de Engenharia Ambiental que participaram como monitores.

Após o preenchimento do questionário pré-atividades, foi exibido um vídeo de curta duração mostrando a evolução da Terra, de sua origem até os dias atuais. Em seguida, o professor mediador fez uma explanação sobre o conceito de "mineral" e das características macroscópicas e genéticas das rochas ígneas, metamórficas e sedimentares, utilizando Datashow como recurso visual. Depois das explicações teóricas, os monitores apresentaram aos alunos participantes, divididos em grupos de até 5 indivíduos, amostras de diferentes minerais e rochas.

Para abordar a evolução da biodiversidade, foi apresentada uma coluna simplificada do tempo geológico e imagens ilustrativas dos períodos iniciais da evolução da Terra e das primeiras formas de vida, representadas por estromatólitos. Por sua vez, para explicação das condições necessárias para a formação e preservação de um fóssil, foi exibido um vídeo de curta duração.

O tempo geológico foi abordado a partir da seleção de alguns intervalos, do Proterozoico até o Plioceno, utilizando réplicas de fósseis de organismos representativos de cada um destes. Dentre os exemplares apresentados aos alunos, podem ser destacados organismos pertencentes à Fauna de Ediacara, trilobitas, Mesosaurus brasilienses, dentes de Allosaurus fragilis, Tyrannosaurus rex, Carcharodon megalodon, Smilodon populator, ovo e garra de Oviraptor e coprólito (excremento fossilizado) de dicinodonte.

As apresentações eram finalizadas com uma discussão acerca do surgimento do homem no registro geológico e o impacto ambiental negativo desencadeado pelo homem moderno, acarretando na proposição de uma época geológica própria, denominada “Antropoceno" (ARTAXO, 2014).

\section{Resultados e discussão}

Ao longo do ano de 2017 o projeto Geobiologia recebeu 413 estudantes visitantes do $5^{\mathrm{a}}$ série do ensino fundamental ao $2^{\mathrm{o}}$ ano do ensino médio (Graf. 1), provenientes de escolas estaduais $(68,3 \%)$, municipais $(20,3 \%)$ e particulares $(11,4 \%)$ de Itabira (MG) e região. 
Research, Society and Development, v. 7, n. 7, p. 01-23, e1077302, 2018

ISSN 2525-3409 (CC BY 4.0)

Gráfico 1: Escolaridade dos estudantes participantes do projeto Geobiologia, desenvolvido em Itabira (MG), no ano de 2017.

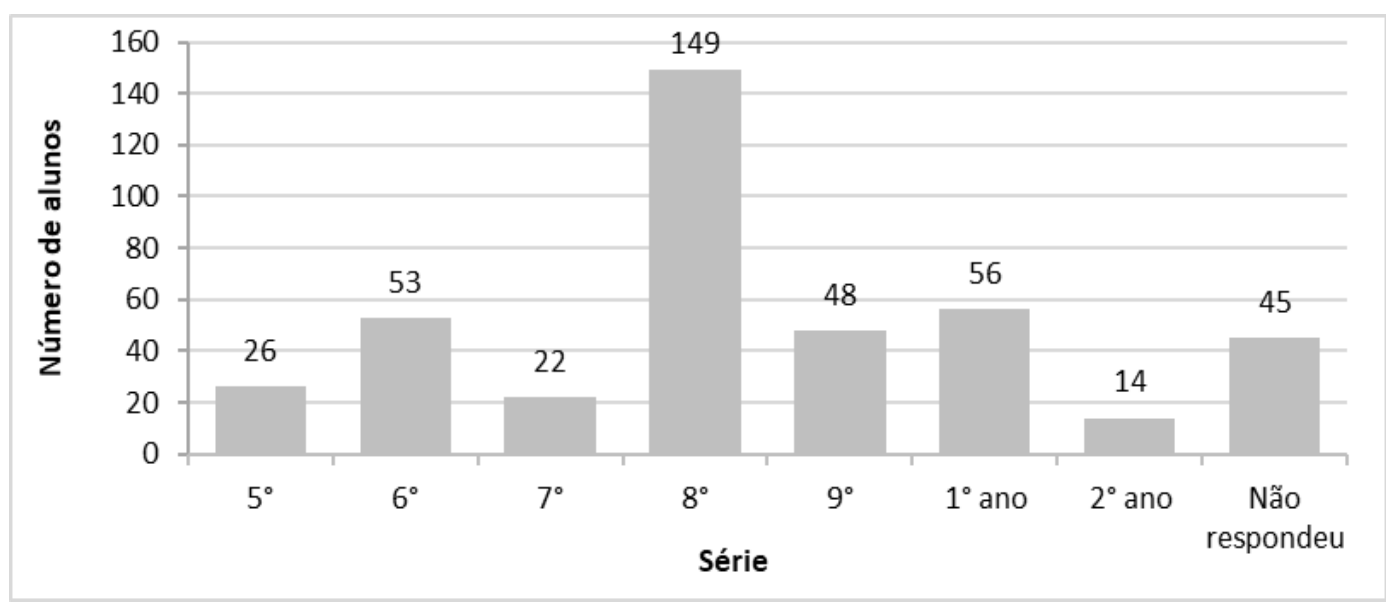

Fonte: Dados da pesquisa, 2017.

De acordo com os Parâmetros Curriculares Nacionais (PCN) o conteúdo do projeto Geobiologia está inserido no eixo temático “Terra e Universo". Desse modo, considerando o terceiro e quarto ciclos, correspondentes, respectivamente, à $5^{\mathrm{a}}-6^{\mathrm{a}}$ séries e $7^{\mathrm{a}}-8^{\mathrm{a}}$ séries, este eixo temático objetiva dentre outros aspectos, a compreensão do Universo, contemplando as transformações que ocorrem na Terra assim como a relação entre seus diversos componentes; o estabelecimento da relação entre os fenômenos naturais, como vulcanismo e terremoto, e os movimentos das placas tectônicas e os conceitos associados à evolução dos seres vivos (BRASIL, 1998). Assim, pode-se associar a maior participação no projeto de alunos de $5^{\mathrm{a}}$ a $8^{\mathrm{a}}$ série à similitude entre os objetivos do projeto Geobiologia, que visa divulgar as ciências naturais na busca pela assimilação da formação, evolução e futuro da vida na Terra e aqueles propostos no PCN para os ciclos em questão.

Quando considerada a origem do Universo, a busca pela sua compreensão, assim como do homem, remonta às mais antigas mitologias conhecidas (GROTZINGER; JORDAN, 2013). A explicação atualmente mais aceita no meio científico para a origem do Universo é a teoria do Big Bang (Grande Explosão), que considera que o Universo surgiu entre 13,5 e 14 bilhões de anos atrás como resultado de uma "explosão" cósmica (COMINS; KAUFMANN III, 2011).

Desse modo, no questionário aplicado, a pergunta sobre a idade do Universo continha as opções de resposta: a) 230 milhões de anos (Ma); b) 4 bilhões de anos (Ga); c) 5 bilhões de anos e d) 14 bilhões de anos. Nota-se, que 45,5\% dos alunos indicaram a opção "d" no questionário pré-atividades, enquanto $91,8 \%$ dos alunos escolheram essa opção após o 
Research, Society and Development, v. 7, n. 7, p. 01-23, e1077302, 2018

ISSN 2525-3409 (CC BY 4.0)

desenvolvimento das atividades, indicando a fixação da informação, apresentada com a exibição de um vídeo no início das ações vinculadas ao projeto (Graf. 2).

Gráfico 2: Respostas fornecidas pelos alunos participantes do projeto Geobiologia, desenvolvido em Itabira (MG), quanto à idade do Universo.

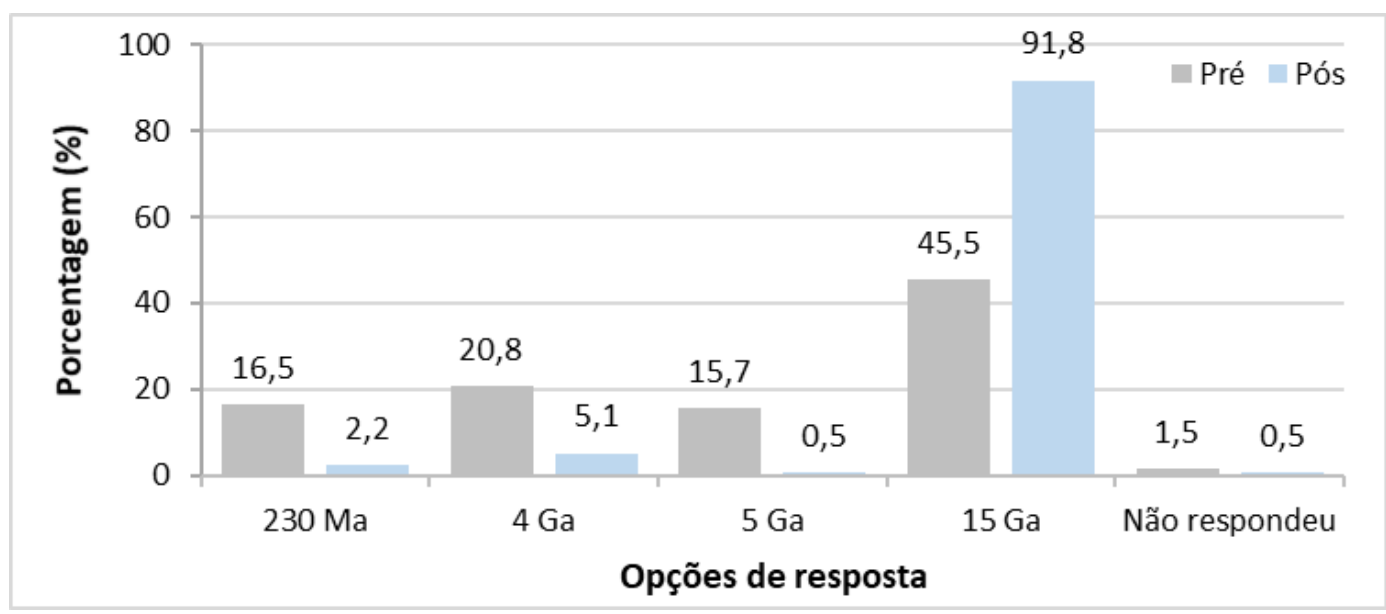

Fonte: Dados da pesquisa, 2017.

Apesar da breve explicação acerca da origem do Universo fornecida no projeto Geobiologia, ressalta-se o potencial deste tema para despertar o interesse científico nos alunos visitantes, observado tanto pela participação destes no desenvolvimento da atividade quanto no comentário "Foi muito interessante aprender novas coisas sobre o universo" (alunos de $8^{\mathrm{a}}$ série e $9^{\circ}$ ano provenientes de escola municipal, visita realizada em agosto/2017).

Contudo, Langhi (2004) ressalta que, apesar das características interdisciplinares da Astronomia, as quais possibilitam sua interação com praticamente todas as disciplinas, e do seu potencial educativo, observa-se um afastamento desta ciência dos currículos escolares, praticamente inexistindo nos cursos de formação de professores, especialmente daqueles do Ensino Fundamental, resultando em dificuldades associadas ao ensino de Ciências para as crianças.

Semelhantemente, quando considerada a inclusão do tema Cosmologia no ensino da Física, Skolimoski (2014) destaca, como dificuldades, a formação acadêmica dos docentes, uma vez que a maioria dos professores desta disciplina é graduada em áreas do conhecimento correlatas e a ausência de contato dos docentes com licenciatura em física e o tema cosmologia ao longo da sua formação, dentre outros aspectos. Entretanto, a autora salienta o potencial do tema Cosmologia para despertar nos alunos o interesse pelo conhecimento 
Research, Society and Development, v. 7, n. 7, p. 01-23, e1077302, 2018

ISSN 2525-3409 (CC BY 4.0)

científico, que, "pode passar de mera curiosidade ingênua, para uma curiosidade mais refinada e importante" (SKOLIMOSKI, 2014, p. 201).

O planeta Terra é formado pelos mesmos materiais que constituem os demais corpos do Sistema Solar e tudo o mais que faz parte do Universo. A origem da Terra está relacionada diretamente à formação do Sol, dos demais planetas do Sistema Solar, além de todas as estrelas a partir de nuvens de gás e poeira interestelar (TEIXEIRA et al., 2001). Por outro lado, a Geologia examina apenas os últimos 4,5 bilhões de anos da expansão do Universo, período este no qual o sistema solar (incluindo o Sol e o planeta Terra) foi formado e evoluiu (GROTZINGER; JORDAN, 2013).

Com relação à idade da Terra, o questionário aplicado possuía as alternativas: a) 2017 anos; b) 200 milhões de anos, c) 4,5 bilhões de anos e d) 4 bilhões de anos. É possível observar no Gráfico 3 que 61,5\% dos alunos escolheram a opção "c” no questionário respondido antes das atividades, ao passo que $88,8 \%$ indicaram essa mesma resposta após as atividades, novamente indicando a fixação da informação, apresentada por meio de imagens projetadas com Datashow.

Gráfico 3: Respostas fornecidas pelos alunos participantes do projeto Geobiologia, desenvolvido em Itabira (MG), quanto à idade da Terra.

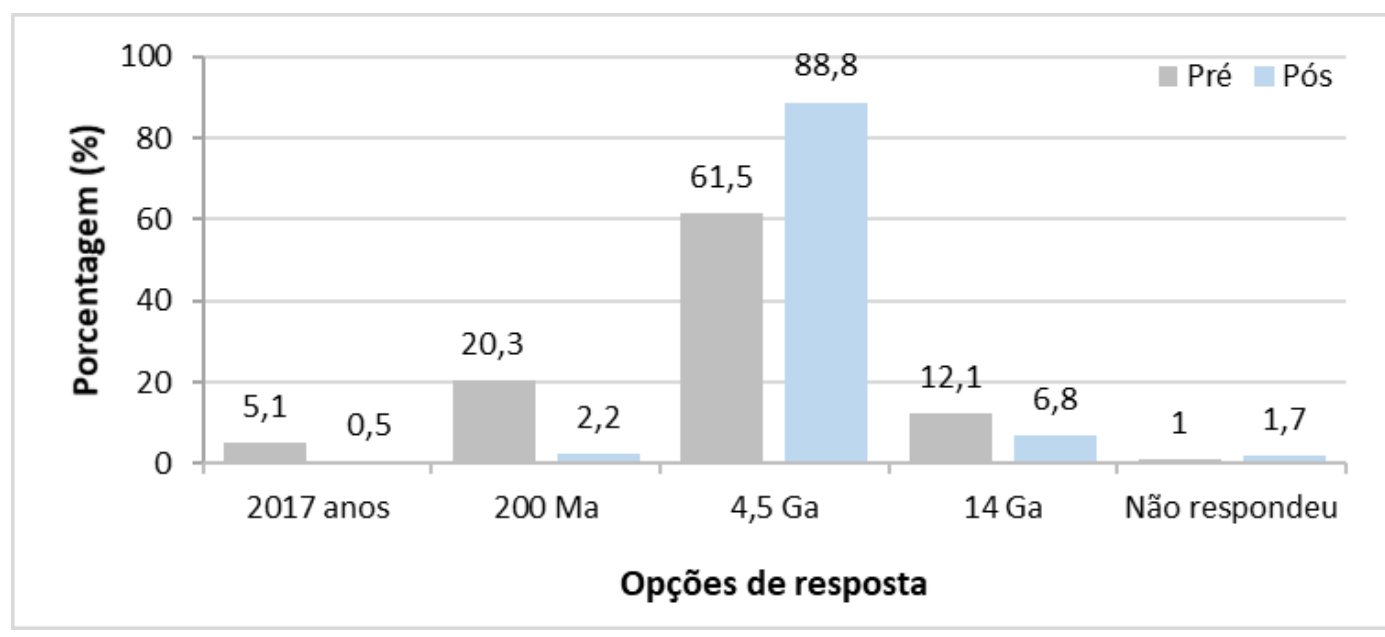

Fonte: Dados da pesquisa, 2017.

Inicialmente incandescente, há aproximadamente 4,3 bilhões de anos ocorreu um resfriamento do planeta Terra, que possibilitou a transformação do vapor em água líquida, originando um oceano primitivo (SUGUIO; SUZUKI, 2009). Desde a diferenciação da Terra em litosfera, hidrosfera e atmosfera, há cerca de 4 bilhões de anos, os processos geológicos 
representados pelo plutonismo, vulcanismo, tectonismo, metamorfismo, intemperismo e erosão, dentre outros, ditaram tanto a evolução geológica quanto a biológica do planeta.

A teoria da tectônica de placas explica a origem dos terremotos, vulcões, distribuição de cadeias de montanhas, descrevendo o movimento das placas (fragmentos da litosfera, camada mais externa da Terra) e as forças que atuam entre elas. Cerca de 12 placas tectônicas deslizam, convergindo ou se separando umas com relação às outras, sobre a astenosfera, que também está em movimento. Apesar de algumas placas receberem o nome dos continentes que abarcam, nenhuma placa é análoga a um continente (GROTZINGER; JORDAN, 2013).

Assim, os alunos participantes dessa pesquisa tinham as seguintes alternativas para descreverem a teoria da tectônica de placas: a) chocam entre si nas extremidades da Terra, derretendo as calotas polares; b) correspondem aos limites dos continentes; c) deslizam sobre o material quente do interior da Terra, se aproximando ou se afastando e d) são fixas, por isso os continentes não se movem. Verifica-se no Gráfico 4 que 61,7\% dos respondentes indicaram a opção "c" no questionário pré-atividades, enquanto após as atividades essa resposta foi escolhida por $67,3 \%$ dos estudantes.

Gráfico 4: Respostas fornecidas pelos alunos participantes do projeto Geobiologia, desenvolvido em Itabira (MG), quanto à teoria das placas tectônicas.

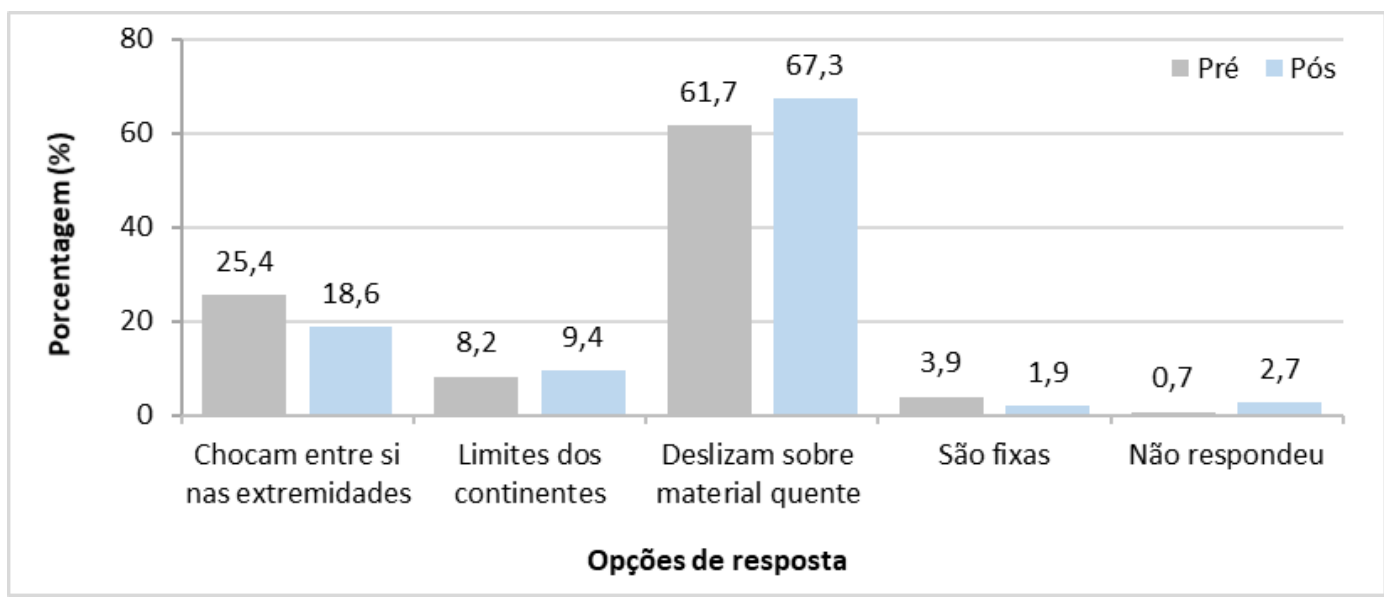

Fonte: Dados da pesquisa, 2017.

Por outro lado, também é possível notar no Gráfico 4 que 9,4\% dos respondentes após as atividades (antes destas a porcentagem correspondia a $8,2 \%$ ), indicaram a opção "b", que afirmava a existência de uma correspondência entre as placas tectônicas e as áreas continentais, sugerindo que apenas a utilização de mapas/imagens e uma explicação verbal não foram suficientes para uma compreensão adequada deste conceito. 
Analisando os obstáculos para o ensino e divulgação da Geologia, Carneiro et al. (2004) destacam, dentre outros, a escala de tempo, uma vez que na maioria dos processos geológicos são envolvidos valores de muitos milhões de anos, o que poderia tornar a linguagem utilizada pelos geólogos irrelevante quando considerada a necessidade de resolução, em tempo útil, de adversidades atuais.

De maneira geral, os estratos rochosos podem ser ordenados e correlacionados em uma sequência temporal de eventos geológicos a partir das idades relativas das rochas sedimentares utilizando tanto a regra da superposição como o registro fossilífero local e global; através da deformação e discordâncias angulares para datar os eventos tectônicos em relação à sequência estratigráfica e por meio das relações de seccionamento para determinar as idades relativas de corpos ígneos ou falhas que "cortem" as rochas sedimentares. Assim, nos séculos XIX e XX, os geólogos utilizaram estes princípios de datação relativa aliados às informações de afloramentos de todo o mundo para adaptar uma escala do tempo geológico, que corresponde a um calendário de idades relativas da história geológica da Terra (PRESS et al., 2006; CERVATO, FRODEMAN, 2013).

Faz-se importante salientar que os fósseis consistem no registro em rochas da existência de organismos, que podem se apresentar sob a forma de fósseis corporais (restos) ou apenas vestígios da atividade dos seres vivos, conhecidos como icnofósseis (CARVALHO, 2004). Há ainda vários núcleos de estudos, tais como Paleobotânica (fósseis de plantas em geral), Paleontologia de Vertebrados, Paleontologia de Invertebrados (moluscos, braquiópodes, equinóides, conchostráceos, dentre outros), Micropaleontologia e Paleoicnologia, esta última consistindo na pesquisa de icnofósseis (CASSAB, 2004). Considerando a Micropaleontologia, destacam-se os estudos dos foraminíferos, nanofósseis calcários, radiolários, tintinídeos, calpionelídeos, diatomáceas, dinoflagelados, ostracodes, quitinozoários e acritarcos (CARVALHO, 2004).

A escala do tempo geológico é dividida em quatro unidades principais de tempo: éons, eras, períodos e épocas. Um éon corresponde à maior divisão da história, sendo que o mais antigo é o Arqueano, representado por rochas com cerca de 4 bilhões de anos até 2,5 bilhões de anos, durante o qual os sistemas do geodínamo, da tectônica de placas e do clima da Terra foram estabelecidos. Além disso, os fósseis de organismos unicelulares primitivos são encontrados em algumas rochas sedimentares dessa idade (PRESS et al., 2006).

Já o Éon Proterozoico (de 2,5 bilhões a 543 milhões de anos atrás) é marcado pela precipitação, na água do mar, de grandes quantidades de óxido de ferro, além de interações do geossistema da tectônica de placas e do clima semelhantes àquelas que ocorreram em tempos 
geológicos posteriores (PRESS et al., 2006). Com relação às evidências fósseis, tem-se a identificação dos primeiros organismos eucariontes, a cerca de 2,7 bilhões de anos, com a diversificação destes ocorrendo entre 1,2 - 1,0 bilhões de anos (COCKELL, 2011).

Por fim, o Éon Fanerozoico, o mais recente éon, abrange os últimos 543 milhões de anos, sendo subdividido em três eras: Era Paleozoica ("vida antiga"), de 543 milhões a 251 milhões de anos atrás; Era Mesozoica ("vida intermediária"), de 251 milhões a 65 milhões de anos atrás; Era Cenozoica ("vida recente"), de 65 milhões de anos atrás até o presente (PRESS et al., 2006). De acordo com Cockell (2011), este Éon é caracterizado por taxas de renovação (aparecimento e desaparecimento de grupos de fósseis) desiguais, com episódios de extinções em massa ao longo de fases de modificações evolucionárias mais lentas.

As eras são subdivididas em períodos, que por sua vez, são subdivididos em épocas. Os períodos, em sua maioria, são determinados de acordo com o nome da localidade geográfica onde as rochas estão melhor expostas ou onde foram descritas pela primeira vez ou, ainda, por alguma característica proeminente das formações (PRESS et al., 2006).

Para abordar a escala de tempo geológico, assim como a evolução da biodiversidade, os estudantes foram questionados acerca das primeiras formas de vida na Terra, tendo como alternativas as seguintes respostas: a) eram peixes com mandíbulas; b) os seres que dominavam eram as plantas terrestres; c) algas simples e seres unicelulares presentes nos mares rasos e d) seres marinhos predadores. É possível perceber no Gráfico 5 que 69\% dos alunos visitantes indicaram a opção "c" antes das atividades, atingindo 73,6\% das respostas após o desenvolvimento das ações vinculadas ao projeto.

Gráfico 5: Respostas fornecidas pelos alunos participantes do projeto Geobiologia, desenvolvido em Itabira (MG), quanto às primeiras formas de vida.

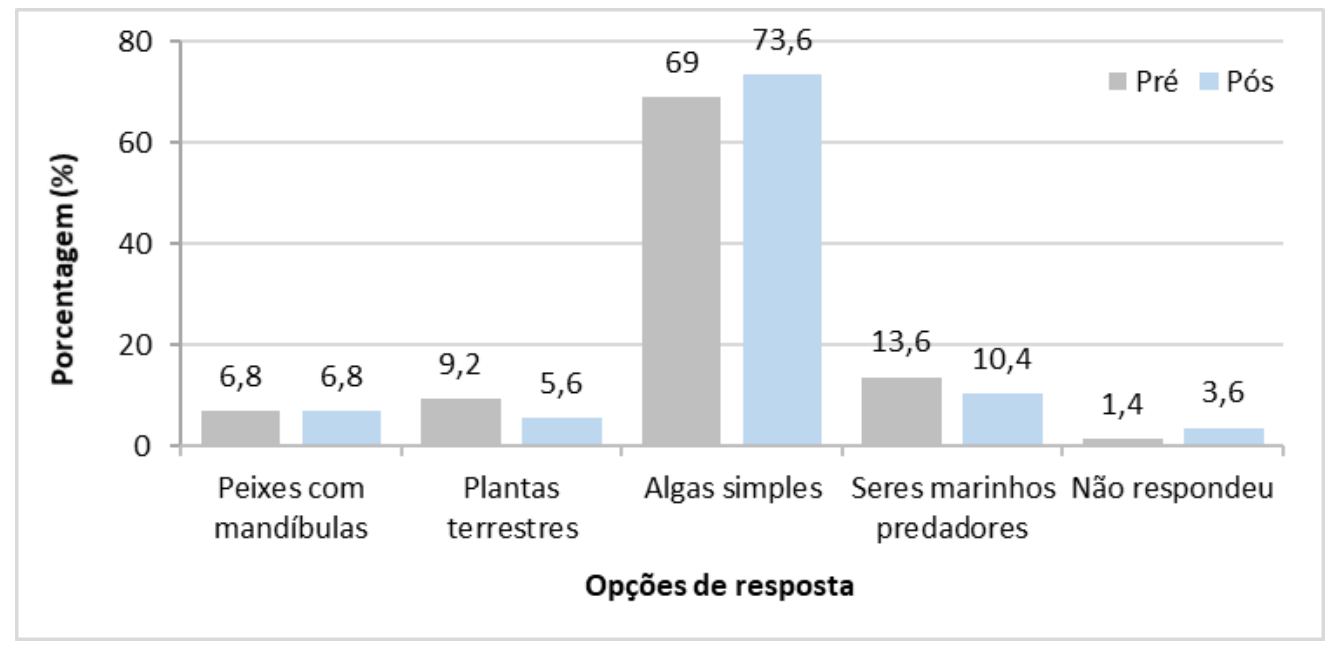

Fonte: Dados da pesquisa, 2017. 
Research, Society and Development, v. 7, n. 7, p. 01-23, e1077302, 2018

ISSN 2525-3409 (CC BY 4.0)

Ressalta-se que a dificuldade dos alunos visitantes para a compreensão das características das primeiras formas de vida na Terra pode estar associada a abordagem utilizada no projeto, restrita à exibição de imagens com Datashow de estromatólitos (estruturas construídas por bactérias em ambientes marinhos) fósseis e atuais, acompanhados por uma breve explanação. Neste contexto, Almeida et al. (2013), assim como evidenciado por Clarck (2002), destacam que exposições de coleções científicas são importantes formas de comunicação entre as instituições de ensino e os visitantes, com essa comunicação sendo caracterizada como adequada quando ocorre o entendimento pertinente dos receptores.

Cada uma das eras do Fanerozoico é caracterizada por um conjunto de fósseis, com o limite entre elas sendo marcado por mudanças profundas deste conjunto (SALGADOLABOURIAU, 1994). Dessa forma, a Era Paleozoica, por exemplo, se iniciou com uma explosão de novas formas de vida e terminou com uma extinção em massa na qual aproximadamente $96 \%$ dos organismos marinhos foram extintos. Assim, a extinção em massa pode ser compreendida como o desaparecimento definitivo de muitas espécies de animais por todo o mundo (COCKELL, 2011).

Considerando o significado da expressão "extinção em massa", os alunos tinham as seguintes opções: a) extinção da vida marinha do Período Cambriano; b) queda de um asteroide que causou somente a extinção dos dinossauros; c) várias extinções que ocorreram ao longo da escala geológica que causaram a diminuição considerável da biodiversidade e d) extinção das plantas terrestres. Nota-se no Gráfico 6, que inicialmente 83,5\% dos alunos escolheram a opção “c”, sendo que esta alternativa atingiu $88,4 \%$ das respostas após o desenvolvimento das atividades.

Gráfico 6: Respostas fornecidas pelos alunos participantes do projeto Geobiologia, desenvolvido em Itabira (MG), quanto ao significado de "extinção em massa".

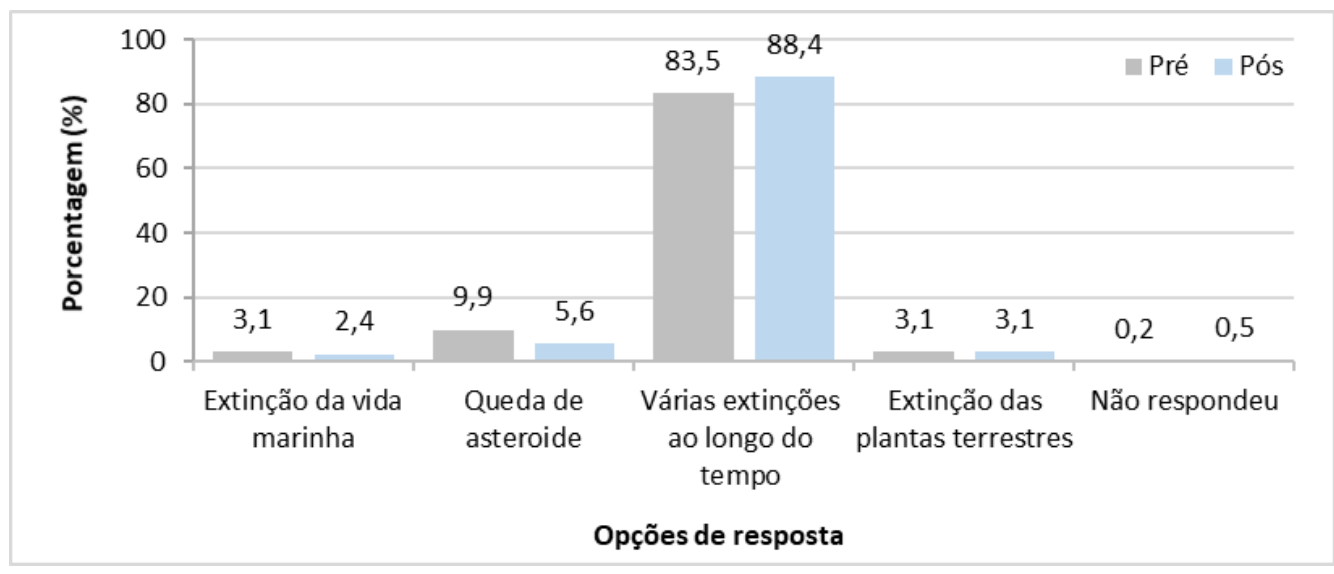

Fonte: Dados da pesquisa, 2017. 
Research, Society and Development, v. 7, n. 7, p. 01-23, e1077302, 2018

ISSN 2525-3409 (CC BY 4.0)

A Era Mesozoica é dividida nos períodos Triássico (251 a 201 milhões de anos), Jurássico (201 a 145 milhões de anos) e Cretáceo (145 a 65 milhões de anos). Durante esse intervalo de tempo ocorreram modificações significativas nos continentes por fragmentação e deriva, assim como a formação de novos oceanos, as quais acarretaram em mudanças relevantes no meio físico (SALGADO-LABOURIAU, 1994).

$\mathrm{Na}$ Era Mesozoica surgiram novos tipos de insetos, como os insetos sociais (tais como formigas, abelhas e cupins); as angiospermas (plantas com flores contendo sementes); e, no final do Triássico, a fauna de grandes animais (abarcando uma diversidade de répteis mamaliformes) foi substituída pelos dinossauros; além disso, nessa era surgiram os mamíferos, aves e tipos modernos de répteis e anfíbios (POUGH et al., 2008).

Salienta-se que no limite inferior dessa Era ocorreu uma grande extinção em massa, com causas ainda incertas, mas de algum modo associadas a um evento glacial que afetou o planeta (PIETROBELLI; TRATZ, 2015). Já no limite superior da Era Mesozoica, o final do período Cretáceo também é caracterizado por outra grande extinção, atribuída a um impacto de meteoro ou asteroide, que além de resultar na morte dos dinossauros, afetou muitos tipos de organismos, como invertebrados, plantas e vertebrados não dinossauros (POUGH et al., 2008).

Considerando os seres vivos que predominavam no Jurássico, os estudantes possuíam as seguintes opções: a) seres humanos; b) peixes com mandíbulas; c) plantas aquáticas como as algas e d) grandes répteis. É possível verificar no Gráfico 7 que 88,4\% dos alunos indicaram a opção "c" no questionário pré-atividades, ocorrendo uma redução dessa porcentagem (84\%) após o desenvolvimento das ações vinculadas ao projeto.

Gráfico 7: Respostas fornecidas pelos alunos participantes do projeto Geobiologia, desenvolvido em Itabira (MG), quanto aos seres que predominavam no Período Jurássico.

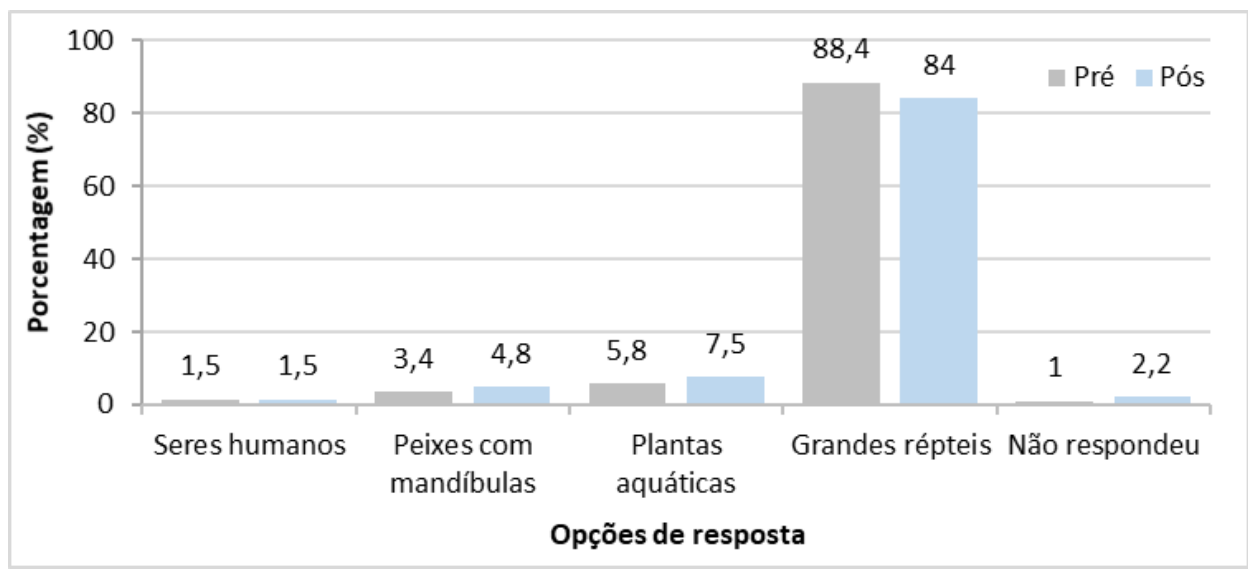

Fonte: Dados da pesquisa, 2017. 
Uma possível explicação para a redução da porcentagem de respostas corretas (alternativa “c"), verificada no questionário pós-atividades, pode estar associada à ênfase dada aos seres que viveram no Período Cretáceo, dada a disponibilidade de réplicas de fósseis desse intervalo de tempo como, por exemplo, garra de Deinonychus antirrhopus, garra e ovo de Oviraptor e dentes de Tyrannosaurus rex e Edmontosaurus annectens, em detrimento do exemplar de dente de Allosaurus fragilis, única peça do acervo utilizado no projeto associada ao Período Jurássico.

A Era Cenozoica, iniciada a 65 milhões de anos atrás se estende até os dias atuais, é conhecida como a Idade dos Mamíferos (ou das Angiospermas, dependendo da ênfase da análise: se nos animais ou nas plantas), sendo caracterizada, dentre outros aspectos, pela diversificação de mamíferos, incluindo os primatas e o homem moderno (SALGADOLABOURIAU, 1994).

Com relação à era geológica caracterizada pela evolução do homem, os alunos participantes do projeto Geobiologia tinham as alternativas: a) Pré-Cambriano; b) Paleozoico; c) Cenozoico e d) Mesozoico. É possível verificar que 22,5\% dos alunos indicaram a opção “c" no questionário pré-atividades, ocorrendo um aumento dessa porcentagem $(53,8 \%)$ após o desenvolvimento das ações do projeto (Graf. 8). Faz-se importante destacar que nas atividades desenvolvidas no projeto buscou-se apenas posicionar o surgimento dos primeiros hominídeos na coluna do tempo geológico, sem detalhar a história evolutiva do homem moderno.

Gráfico 8: Respostas fornecidas pelos alunos participantes do projeto Geobiologia, desenvolvido em Itabira (MG), quanto à era geológica caracterizada pelo surgimento do homem.

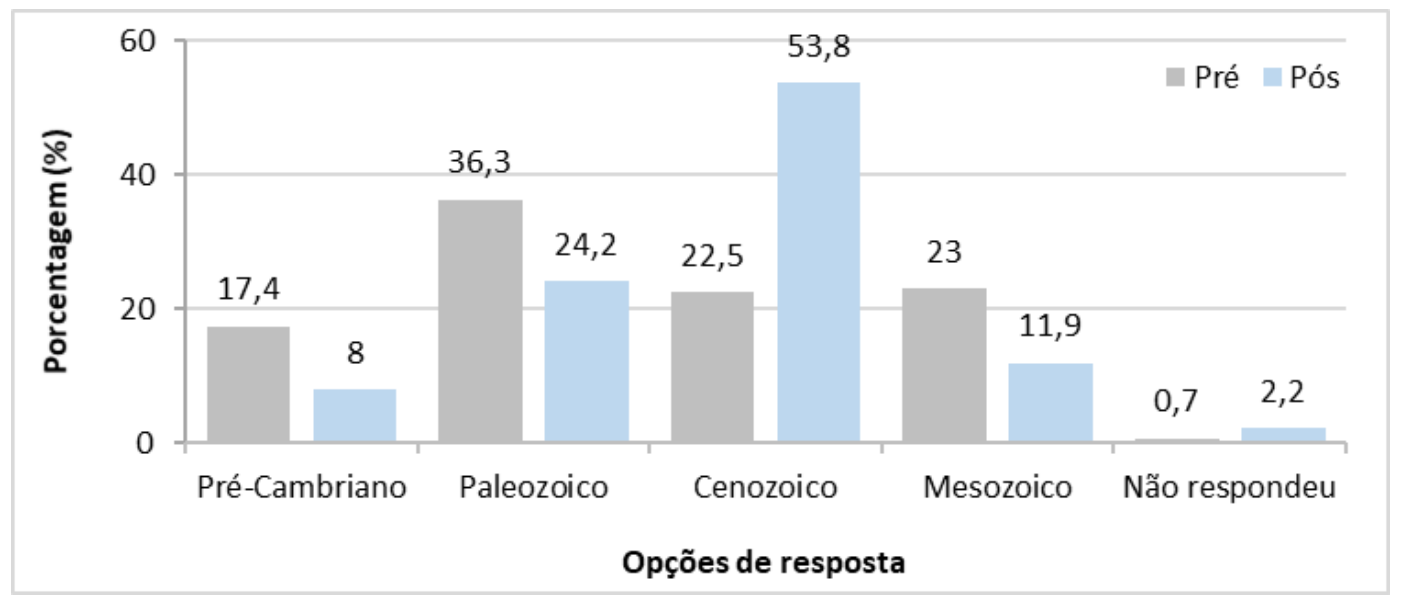

Fonte: Dados da pesquisa, 2017. 
Research, Society and Development, v. 7, n. 7, p. 01-23, e1077302, 2018

ISSN 2525-3409 (CC BY 4.0)

A espécie humana é capaz de afetar de forma significativa a abundância e a sobrevivência de outras espécies de um modo nunca antes observado na história da Terra. Os avanços tecnológicos, iniciados com as ferramentas líticas há cerca de 2,5 milhões de anos, separam os humanos de outras espécies de vertebrados, permitindo a utilização de recursos naturais. Contudo, a extração e o consumo desses recursos pelas sociedades humanas desencadeiam impactos globais, abarcando desde as contaminações do solo e da água por metais tóxicos até a perda de habitats naturais para a urbanização e agricultura (POUGH et al., 2008).

Neste contexto faz-se importante a inserção do conceito de "meio ambiente", que de acordo com a Política Nacional do Meio Ambiente, instituída pela Lei $n^{\circ}$ 6.938/1981, pode ser definido como "o conjunto de condições, leis, influências e interações de ordem física, química e biológica, que permite, abriga e rege a vida em todas as suas formas" (BRASIL, 1981, Art. $\left.3^{\circ}\right)$.

As opções disponíveis no questionário quanto ao conceito de meio ambiente correspondiam: a) somente aquilo que tem utilidade para o ser humano; b) todos os elementos e seres vivos que habitam o planeta e suas relações sociais, econômicas e ambientais; c) apenas as matas, animais, água e ar e d) somente as interações entre o meio físico. Verifica-se no Gráfico 9 que, quando considerado o pré-questionário, 88,4\% dos alunos indicaram a opção "b", porém, após o desenvolvimento das atividades, houve uma diminuição das respostas corretas (80,4\%), além de um aumento de respostas (de 9,9\% para 13,8\%) associadas à alternativa "c" (Graf. 9).

Gráfico 9: Respostas fornecidas pelos alunos participantes do projeto Geobiologia,

desenvolvido em Itabira (MG), quanto à definição de "meio ambiente".

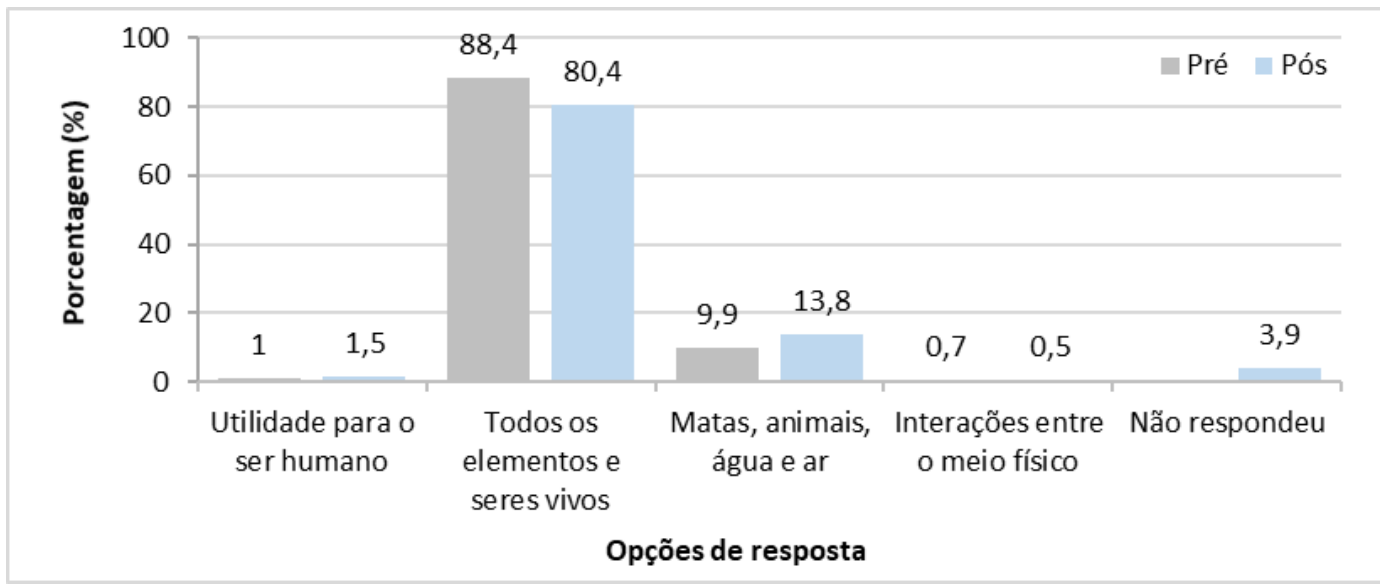

Fonte: Dados da pesquisa, 2017. 
Research, Society and Development, v. 7, n. 7, p. 01-23, e1077302, 2018

ISSN 2525-3409 (CC BY 4.0)

Salienta-se que a abordagem utilizada no projeto, destacando o surgimento do homem no Cenozoico, pode ter influenciado a compreensão do conceito de meio ambiente sob uma perspectiva naturalista. Assim, mostram-se essenciais modificações nas atividades desenvolvidas no projeto, buscando promover a sensibilização, assim como desenvolver nos alunos visitantes a percepção e compreensão do ambiente.

Além disso, ressalta-se a importância da educação ambiental como possível solução para os problemas ambientais, como a desertificação e a ocupação de áreas de risco geológico, por proporcionar o entendimento do papel do indivíduo diante das mudanças observadas no planeta e da sua responsabilidade frente a essas transformações (BACCI, 2009).

Assim, na última questão do questionário os alunos visitantes precisavam relacionar as ações causadas pelo homem na natureza, sendo possível a seleção de mais de uma opção. Considerando as respostas fornecidas no pré-questionário, podem-se destacar no Gráfico 10 as ações humanas representadas pelo desmatamento $(97,1 \%)$, poluição da água $(96,4 \%)$, poluição do ar $(96,2 \%)$, extinção $(95,2 \%)$ e poluição do solo $(92,5 \%)$. Por outro lado, os alunos destacaram que o homem não é responsável pelo vulcanismo (97,9\%), tsunamis (97,1\%), chuva ácida $(80,4 \%)$ e terremotos $(67,8 \%)$.

Gráfico 10: Respostas fornecidas pelos alunos participantes do projeto Geobiologia, desenvolvido em Itabira (MG) sobre as ações do homem na natureza, questionário préatividades.

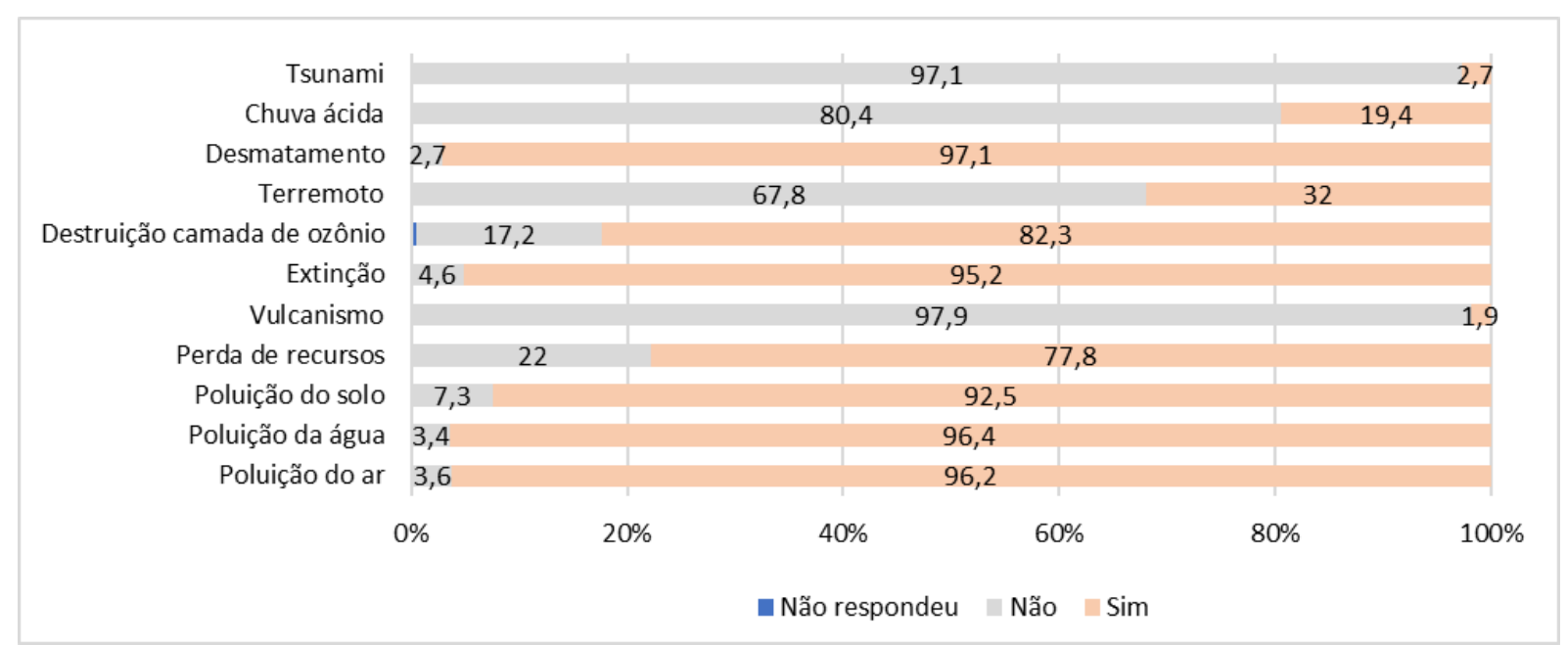

Fonte: Dados da pesquisa, 2017. 
Research, Society and Development, v. 7, n. 7, p. 01-23, e1077302, 2018

ISSN 2525-3409 (CC BY 4.0)

Com relação ao questionário pós-atividades (Graf. 11) podem ser salientadas as ações humanas representadas pelo desmatamento $(97,3 \%)$, poluição da água $(97,3)$, poluição do ar $(95,6 \%)$, poluição do solo $(95,1 \%)$ e extinção $(93,9 \%)$. Por outro lado, os alunos visitantes destacaram que o homem não é responsável pelo vulcanismo (97,8\%), tsunamis $(97,3 \%)$, terremotos $(95,9 \%)$ e chuva ácida $(54,5 \%)$.

Gráfico 11: Respostas fornecidas pelos alunos participantes do projeto Geobiologia, desenvolvido em Itabira (MG), sobre as ações do homem na natureza, questionário pósatividades.

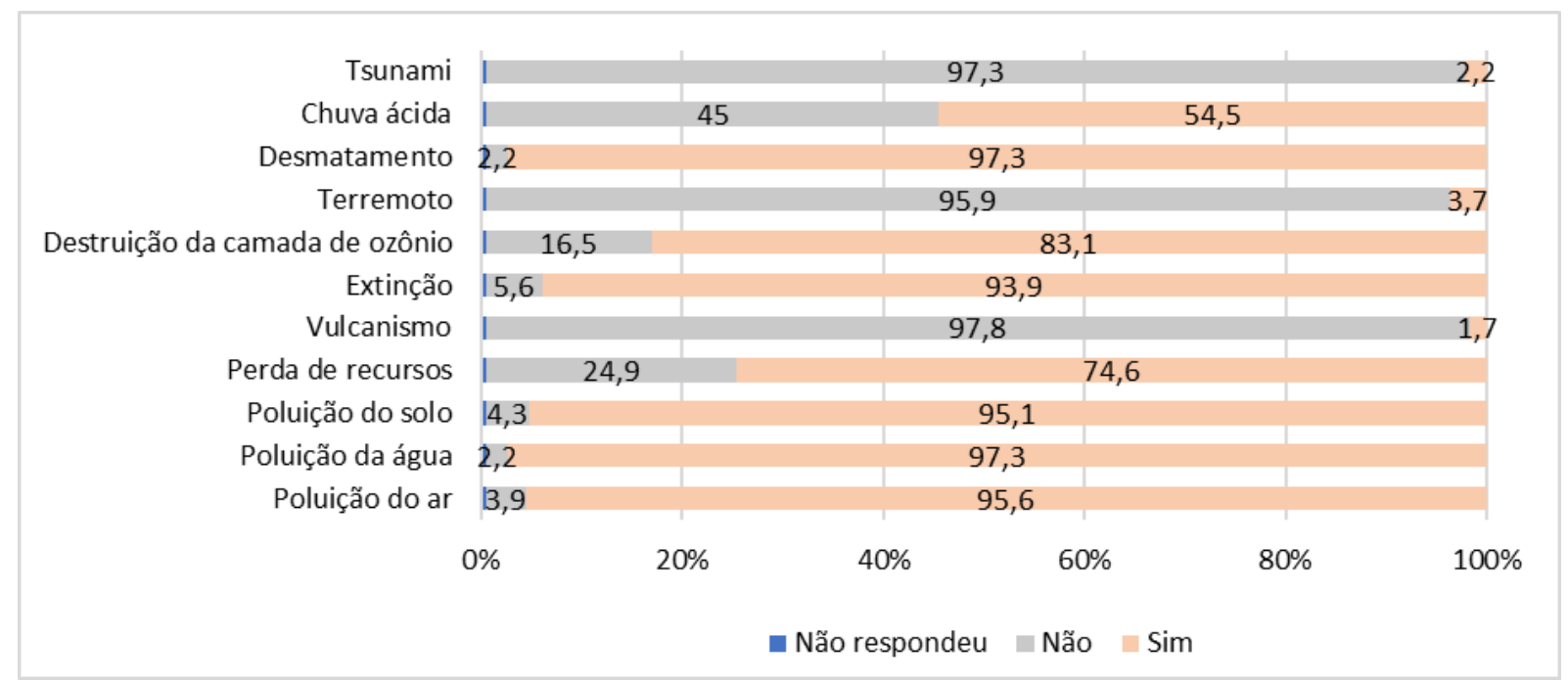

Fonte: Dados da pesquisa, 2017.

A partir dos dados apresentados nos Gráficos 10 e 11, verificam-se modificações associadas principalmente ao aumento das respostas corretas quanto ao item "chuva ácida" (alteração de 19,4\% para 54,5\% das respostas) e "terremoto" (alteração de 67,8\% para 95,9\% das respostas). Com relação a este último item, os dados obtidos indicam que apesar do conceito de "placas tectônicas" não ter sido totalmente assimilado pelos alunos visitantes, a distribuição dos terremotos e vulcões, associada aos limites dessas placas foi compreendido de forma satisfatória.

Após o desenvolvimento das atividades e preenchimento do questionário, os alunos visitantes, divididos em grupos de 3 a 5 participantes, foram convidados a preencherem um segundo questionário para avaliação do projeto. Para tal, deviam ser utilizados os conceitos "Muito bom", "Bom" e "Ruim", com relação aos itens "Duração da atividade", "Local da atividade", "Sua opinião sobre a atividade" e "Avaliação da atividade como um todo"; além disso, os alunos visitantes podiam apresentar sugestões, críticas ou observações. Os resultados 
obtidos nesta avaliação, considerando a amostra composta por 75 questionários, são apresentados no Gráfico 12.

Gráfico 12: Avaliação dos alunos participantes sobre as atividades desenvolvidas no projeto Geobiologia, Itabira (MG).

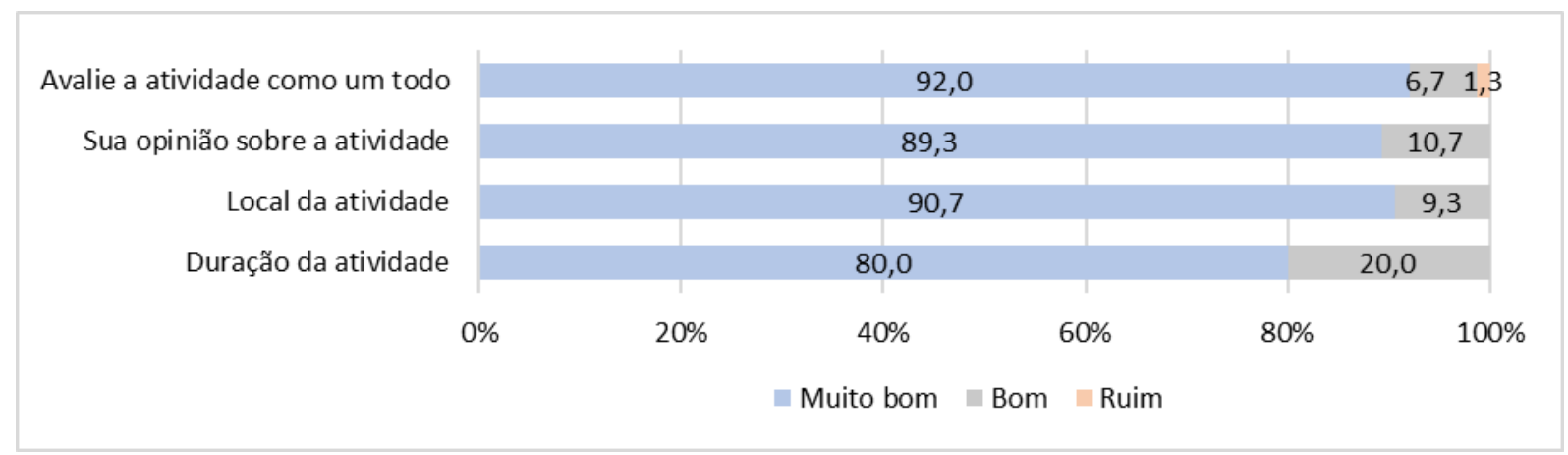

Fonte: Dados da pesquisa, 2017.

Apesar das avaliações predominantemente "muito boas", destaca-se uma menor porcentagem desta (correspondendo a 80,0\%) com relação ao item "Duração da atividade". Neste sentido, considerando o preenchimento dos questionários (antes e após as atividades), as explanações utilizando Datashow e vídeos, e o manuseio de exemplares de minerais, rochas e réplicas de fósseis, a duração de cada visita foi de aproximadamente 100 minutos, o que pode justificar a dificuldade da manutenção da atenção dos alunos durante toda a atividade.

Com relação ao local da atividade, apesar da avaliação de 90,7\% dos alunos visitantes como "muito bom", destaca-se o comentário: "Quem senta atrás não consegue ver muito bem o slide" (alunos da $8^{\text {a }}$ série $/ 9^{\circ}$ ano, provenientes de escola municipal, visita realizada em agosto/2017). Neste contexto, todas as atividades são conduzidas no Laboratório de Geologia, preparado para a realização das aulas práticas das disciplinas "Elementos de Ciência do Solo" e "Geologia", ofertadas, respectivamente, nos cursos de Engenharia Ambiental e Engenharia Civil. Assim, como a infraestrutura do laboratório não foi projetada para atender crianças, busca-se, durante o desenvolvimento das atividades do projeto, a realocação destas em função da sua estatura, de tal forma que todos possam visualizar as imagens e vídeos exibidos.

Por fim, a avaliação "muito boa" da atividade como um todo (correspondendo a 92,0\% das respostas obtidas), pode ser atribuída à possibilidade de os alunos visitantes manipularem todos exemplares do acervo utilizado no projeto. Destacam-se os comentários: "Uma coisa legal na atividade foi que podíamos pegar nos materiais e ver vídeos e slides" (alunos da $6^{\text {a }}$ 
série ao $9^{\circ}$ ano, provenientes de escola estadual, visita realizada em maio/2017); "As explicações foram muito boas, ver os fósseis, os minerais e as rochas foi uma experiência incrível, pelo fato de aprendermos um pouco sobre cada coisa" (alunos do $2^{\mathrm{o}}$ e $3^{\mathrm{a}}$ anos, provenientes de escola estadual, visita realizada em setembro/2017); “É legal aprender sobre fóssil e como a Terra foi formada, gostamos de ver os fósseis" (alunos da $6^{\mathrm{a}}$ a $8^{\mathrm{a}}$ séries, provenientes de escola estadual, visita realizada em abril/2017).

Nesta acepção, ao pesquisarem a percepção de 439 alunos do ensino médio de uma escola de Realengo (RJ), Firmino et al. (2013) verificaram que a maior parte dos alunos, apesar de desconhecerem o conceito de Geociências, demonstraram interesse em temas como "universo", "impactos ambientais" e "planeta Terra", além de acreditarem que aprenderiam mais por meio de aulas dinâmicas, utilizando experimentos e Datashow/vídeos e jogos/dinâmicas em grupo. De forma semelhante, Vieira et al. (2016), analisando a percepção de alunos do $6^{\circ}$ ano do ensino fundamental de uma escola privada de Duque de Caxias (RJ), notaram o interesse destes nos temas "universo", "vulcanismo" e "planeta Terra", destacando que o baixo interesse em alguns temas pode estar relacionado à ausência de diversificação de recursos didáticos.

\section{Considerações finais}

A Geologia é o campo da ciência que estuda os processos físicos e químicos que controlam a Terra, já a Biologia corresponde ao estudo da vida, assim como dos organismos vivos, abrangendo sua estrutura, função, origem e evolução. O vínculo entre essas ciências possibilitou o surgimento da Geobiologia, que corresponde ao estudo das interações envolvendo o ambiente físico da Terra e a biosfera.

Neste sentido, o projeto Geobiologia, desenvolvido na Fundação Comunitária de Ensino Superior de Itabira - FUNCESI (MG) por professores e alunos desta, visa a divulgação das ciências envolvidas na busca pela compreensão da formação, evolução e futuro da vida na Terra, utilizando para isso atividades práticas e equipamentos audiovisuais. Dessa forma, este trabalho objetou analisar a percepção dos alunos visitantes acerca dos conceitos de geociências, verificada por meio de questionário aplicados antes e após as atividades desenvolvidas.

A partir da comparação das respostas fornecidas nos questionários, notou-se, de maneira geral, a assimilação pelos alunos visitantes de conceitos vinculados às origens do 
Universo e da Terra, apresentados por meio de explanações, imagens e vídeos de curta duração. Por outro lado, verificou-se que a utilização desses mesmos recursos não foi suficiente para a compreensão adequada dos conceitos associados a tectônica de placas e primeiras formas de vida na Terra.

Apesar de uma abordagem breve e com ênfase somente no posicionamento dos primeiros hominídeos na coluna do tempo geológico, a era geológica associada à evolução do homem (Cenozoico) foi assimilada pela maioria dos alunos visitantes. Por sua vez, essa mesma abordagem pode ter influenciado a percepção dos alunos quanto ao conceito de "meio ambiente", resultando em uma visão naturalista por parte dos alunos após as atividades e indicando a necessidade de modificações nas ações atreladas ao projeto.

Por fỉm, a utilização de réplicas de fósseis e a manipulação de minerais e rochas, foram descritas pelos alunos visitantes como a parte mais "legal" do projeto. Ressalta-se que essas ações tornaram as atividades mais dinâmicas, despertando o interesse e a curiosidade dos alunos envolvidos.

Por meio das atividades desenvolvidas pelo projeto Geobiologia, espera-se que os alunos participantes alcancem uma melhor compreensão da correlação entre as várias ciências da natureza e suas aplicações no cotidiano, despertando a importância da preservação ambiental em todos os setores da sociedade. Além disso, o ensino adequado das ciências naturais pode auxiliar a formar cidadãos mais aptos a enfrentar os inúmeros desafios da sociedade e contribuir para a divulgação do conhecimento, criando condições para que a população participe de debates sobre temas científicos que afetam o cotidiano das pessoas.

\section{Referências}

ALMEIDA, L. F.; ZUCON, M. H.; SOUZA, J. F.; REIS, V. S.; VEIRA, F. S. Ensino de Paleontologia: uma abordagem não-formal no Laboratório de Paleontologia da Universidade Federal de Sergipe. Terræ Didatica, Campinas, v. 10, n. 1, p. 14 - 21, 2013.

APPOLINÁRIO, F. Metodologia da ciência: filosofia e prática da pesquisa. $2^{\mathrm{a}}$ edição. São Paulo: Cengage Learning, 2016.

ARTAXO, P. Uma nova era geológica em nosso planeta: o Antropoceno? Revista USP, n. 103, p. 13-24, 2014. Disponível em: <https://www.revistas.usp.br/revusp/article/viewFile/ 99279/97695.\%20Acesso\%20em\%2018.jul.2016>. Acesso em 06 abr. 2018. 
BACCI, D. C. A contribuição do conhecimento geológico para a educação ambiental. Pesquisa em Debate, edição 11, v. 6, n. 2, jul/dez 2009.

BRASIL. Lei ${ }^{\circ} 6.938$ de 31 de agosto de 1981. Dispõe sobre a Política Nacional do Meio Ambiente, seus fins e mecanismos de formulação e aplicação, e dá outras providências. Disponível em: <http://www.planalto.gov.br/ccivil_03/leis/16938.htm>. Acesso: 28 fev. 2018.

BRASIL. Parâmetros Curriculares Nacionais: Ciências Naturais. Secretaria de Educação Fundamental. Brasília: MEC/SEF, 1998. 138 p. Disponível em: <http://portal.mec.gov.br/ seb/arquivos/pdf/ciencias.pdf>. Acesso em: 20 fev. 2018.

CARNEIRO, C. D. R.; TOLEDO, M. C. M.; ALMEIDA, F. F.M. Dez motivos para a inclusão de temas de Geologia na Educação Básica. Revista Brasileira Geociências, v. 34, n. 4, p. 553-560. 2004.

CARVALHO, I. S. Paleontologia. 2. ed. Rio de Janeiro: Interciência, volume 1, 2004.

CASSAB, R. C. T. Objetivos e Princípios. In: CARVALHO, I.S. (Ed.). Paleontologia. Rio de Janeiro: Interciência, 2004, v. 1, n.1, cap. 1, p. 3-11.

CERVATO, C.; FRODEMAN, R. A importância do tempo geológico: desdobramentos culturais, educacionais e econômicos. Terræ Didatica, v. 10, 67-79, 2013.

CLARCK, G. As exposições vistas pelos olhos dos visitantes. A chave para o sucesso da comunicação em museus. In: Seminário Internacional de Implantação de Centros e Museus de Ciência, Rio de Janeiro, 2002. Anais... Rio de Janeiro: Universidade Federal do Rio de Janeiro (UFRJ), 2002.

COCKELL, C. Sistema Terra-Vida: uma introdução. COCKELL, C. (org.); CORFIELD, R.; EDWARDS, N.; HARRIS, N. São Paulo: Oficina de Textos, 2011.

COMINS, N. F.; KAUFMANN III, W. J. Descobrindo o universo. Tradução técnica: Eduardo Neto Ferreira. 8. ed. Dados eletrônicos. Porto Alegre: Bookman, 2011. 
DANTAS, M. A. T.; ARAÚJO, M. I. O. Novas tecnologias no ensino de Paleontologia: Cdrom sobre os fósseis de Sergipe. Revista Eletrónica de Investigacion em Educación em Ciencias. v. 1, n. 2, p. 27 - 38, 2006. Disponível em: <http://www.scielo.org.ar/ scielo.php?script=sci_arttext\&pid=S1850-66662006000200002>. Acesso em: 23 fev. 2018.

FIRMinO, A. R. A.; BEZERRA, H. P. A.; SANTOS, M. C. P.; RODRIGUES, A. P. C.; RANGEL, J. A Importância de aulas experimentais nos conteúdos de Geociências abordados na disciplina de Biologia do Ensino Básico. Revista Eletrônica Novo Enfoque, v. 17, n. 17, p. $100-105,2013$.

GROTZINGER, J.; JORDAN, T. Para entender a Terra. $6^{\text {a }}$ edição. Porto Alegre: Bookman, 2013.

LANGHI, R. Um estudo exploratório para a inserção da astronomia na formação de professores dos anos iniciais do ensino fundamental. Dissertação (Mestrado em Educação para a Ciência). Faculdade de Ciências, UNESP, Bauru, 2004.

LEITE, F. T. Metodologia científica: métodos e técnicas de pesquisa: monografias, dissertações, teses e livros. Aparecida-SP: Ideias \& Letras, 2008.

MARCONI, M.A; LAKATOS, E.M. Fundamentos de metodologia científica. 5.ed. São Paulo: Atlas, 2003.

PIETROBELli, G.; TRATZ, E. B. Dinâmica natural dos processos do meio físico. Paraná: Unicentro, 2015. Disponível em: <http://repositorio.unicentro.br:8080/jspui/handle/123456789/850>. Acesso em: 24 fev. 2018.

POUGH, F. H.; JANIS, C. M.; HEISER, J. B. A vida dos vertebrados. $4^{\mathrm{a}}$ ed. São Paulo: Atheneu Editora, 2008.

PRESS, F.; GROTZINGER, J.; SIEVER, R.; JORDAN, T. H. Para entender a Terra. 4. ed. Porto Alegre: Bookman, 2006. 
Research, Society and Development, v. 7, n. 7, p. 01-23, e1077302, 2018

ISSN 2525-3409 (CC BY 4.0)

PRODANOV, C.C; FREITAS, E.C. Metodologia do trabalho científico: métodos e técnicas da pesquisa e do trabalho acadêmico. 2. ed. Novo Hamburgo: Universidade Freevale, 2013.

SALGADO-LABOURIAU, M. L. História Ecológica da Terra. São Paulo: Blucher, 1994.

SANTANA, V. R.; SANTOS, W. L. P. Visão socioambiental no ensino de ciências naturais no ensino fundamental. In: VII Encontro Nacional de Pesquisa em Educação em Ciências ENPEC, Florianópolis, 2009. Anais... Belo Horizonte: ABRAPEC, 2009. v. 01. p. CD/ROM.

SKOLIMOSKI, K. N. Cosmologia na teoria e na prática: possibilidades e limitações no ensino. Dissertação (Mestrado). Faculdade de Educação, Instituto de Física, Instituto de Química e Instituto de Biociências. Universidade de São Paulo, 2014.

SUGUIO, K.; SUZUKI, U. A evolução geológica da Terra e a fragilidade da vida. São Paulo: Blucher, 2009.

TEIXEIRA, W.; TOLEDO, M. C. M.; FAIRCHILD, T. R.; TAIOLI, F. Decifrando a Terra. São Paulo: Oficina de Textos, 2001.

TOLEDO, M. C. M. Geociências no Ensino Médio Brasileiro - Análise dos parâmetros curriculares nacionais. Geol. USP Publ. Espec., São Paulo, v. 3, p. 31-44, 2005. Disponível em: <http://www.revistas.usp.br/gusppe/article/view/45368>. Acesso em: 23 fev. 2018.

VIEIRA, T. C.; VELlOSO, A.; RODRIGUES, A. P. C. Estudo de caso sobre ensino de Geociências em uma turma de ensino fundamental da rede privada de Duque de Caxias, RJ. Terræ Didatica, v. 12, n. 3, p. 153-162, 2016. 